\title{
A Survey of the Regulatory Requirements for the Acceptance of Foreign Comparator Products by Participating Regulators and Organizations of the International Generic Drug Regulators Programme
}

\begin{abstract}
Alfredo García-Arieta ${ }^{1}$, Craig Simon ${ }^{2}$, Gustavo Mendes Lima Santos ${ }^{3}$, Iván Omar Calderón Lojero ${ }^{4}$, Zulema Rodríguez Martínez $^{4}$, Clare Rodrigues ${ }^{5}$, Sang Aeh Park ${ }^{6}$, Ji Myoung Kim ${ }^{6}$, Ryosuke Kuribayashi ${ }^{7}$, Yusuke Okada ${ }^{7}$, Arno Nolting ${ }^{8}$, Chantal Pfäffli ${ }^{8}$, Wen-Yi Hung ${ }^{9}$, Christopher Crane ${ }^{10}$, April C. Braddy ${ }^{11}$, Joy van Oudtshoorn ${ }^{12}$, Diego Gutierrez Triana ${ }^{13}$, Mitch Clarke ${ }^{14}$

${ }^{1}$ World Health Organisation (WHO) Prequalification of Medicines Programme and Agencia Española de Medicamentos y Productos Sanitarios (AEMPS), C/ Campezo 1. Edificio 8. Madrid, 28022, Spain. ${ }^{2}$ Health Canada, 101 Tunney's Pasture Driveway, Ottawa ON, Canada K1A 0K9. ${ }^{3}$ Agência Nacional de Vigilância Sanitária (ANVISA). SIA Trecho 5, Área Especial 54, Bloco B, Brasília, Brazil. ${ }^{4}$ Comisión Federal para la Protección contra Riesgos Sanitarios (COFEPRIS), Oklahoma No. 14, Colonia Nápoles, Delegación Benito Juárez, 03810, Ciudad de México, México

${ }^{5}$ Health Sciences Authority (HSA), Health Products Regulation Group, Pre-Marketing Cluster, Therapeutic Products Branch. 11 Biopolis Way, Helios \#11-01, Singapore 138667, Singapore. ${ }^{6}$ Ministry of Food and Drug Safety (MFDS). Osong-eup Heungdeok-gu, Cheongju-si, Chungcheongbuk-do, South Korea. ${ }^{7}$ Pharmaceuticals and Medical Devices Agency (PMDA), Shin-kasumigaseki Building 3-3-2, Kasumigaseki, Chiyoda-ku, Tokyo, Japan. ${ }^{8}$ Swissmedic, Schweizerisches Heilmittelinstitut, Hallerstrasse 7, 3000 Bern 9, Switzerland. ${ }^{9}$ Taiwan Food and Drug Administration (TFDA). 161-2, Kunyang St., Nangang, Taipei, 11561 Taiwan, R.O.C. ${ }^{10}$ Therapeutic Goods Administration (TGA). PO Box 100, Woden ACT 2606, Australia. ${ }^{11}$ U.S. Department of Health and Human Services, Food and Drug Administration (US FDA), Center for Drug Evaluation and Research, Office of Generic Drugs, 10903 New Hampshire Avenue, Silver Spring, MD 20993. ${ }^{12}$ South African Health Products Regulatory Authority (SAHPRA). Civitas Building, 42 Thabo Sehume Street, Pretoria, South Africa. ${ }^{13}$ Instituto Nacional de Vigilancia de Medicamentos y Alimentos (INVIMA). Carrera 10 No. 64-28. Bogotá. Colombia. ${ }^{14}$ New Zealand Medicines and Medical Devices Safety Authority (Medsafe), Ministry of Health, 133 Molesworth Street, Thorndon, Wellington, 6011, New Zealand.
\end{abstract}

Received, October 14, 2018; Accepted, December 27, 2018; Published, December 27, 2018.

ABSTRACT - The acceptance of foreign comparator products is the most limiting factor for the development and regulatory assessment of generic medicines marketed globally. Bioequivalence studies have to be repeated with the local comparator products of each jurisdiction because it is unknown if the comparators of the different countries are the same product, with the consequent duplication of efforts by regulators and industry alike. The regulatory requirements on the acceptability of foreign comparator products of oral dosage forms differ between countries participating in the Bioequivalence Working Group for Generics of the International Pharmaceutical Regulators Programme. Brazil, Colombia, the European Union member States, Japan, Mexico, South Korea and the United States only accept bioequivalence studies with their local comparator. In contrast, Australia, Canada, New Zealand, Singapore, South Africa, Switzerland and Taiwan accept studies with foreign comparators under certain conditions. Canada limits its use to highly soluble drugs with a wide therapeutic range in immediate release products. Australia requires a comparison of the quantitative composition. In contrast, there are fewer restrictions on the acceptance of foreign comparators in New Zealand, Singapore, South Africa, Switzerland and Taiwan. For the WHO Prequalification of Medicines and for developing generics of the essential medicines the WHO lists comparators from different countries. In conclusion, there is currently no consensus amongst regulators on the acceptability of foreign comparator products.

\section{INTRODUCTION}

The availability of quality generic products plays an increasingly important role in promoting access to medicines worldwide and in helping to address rising health care costs. This, however, has led to significant pressures on medicines regulatory authorities charged with the review and approval of these products.

The International Generic Drug Regulators
Programme (IGDRP) was created to promote collaboration and convergence among generic drug regulators in order to address the challenges posed by increasing workloads, globalisation and complexity of scientific issues.

Corresponding Author: Alfredo García-Arieta, División de Farmacología y Evaluación Clínica, Subdirección General de Medicamentos de Uso Humano, Agencia Española de Medicamentos y Productos Sanitarios, C/ Campezo 1. Edificio 8, Planta 2 Oeste, E-28022 Madrid, Spain; E-mail: agarciaa@aemps.es 
The IGDRP has now merged with the International Pharmaceutical Regulators Forum to form the International Pharmaceutical Regulators Programme (IPRP). The work that was begun by the Bioequivalence Working Group (BEWG) of IGDRP continues as part of the IPRP.

The Bioequivalence Working Group for Generics (BEWGG) of IPRP aims to promote greater collaboration, regulatory convergence, and potential mutual reliance on respective bioequivalence assessments in the longer term. This group is composed of the following regulators/agencies: Agência Nacional de Vigilância Sanitária (ANVISA, Brazil), Federal Commission for the Protection against Sanitary Risks (COFEPRIS, Mexico), European Commission / European Medicines Agency (EC / EMA), Health Canada (HC), the Health Sciences Authority (HSA, Singapore), Instituto Nacional de Vigilancia de Medicamentos y Alimentos (INVIMA, Colombia), the South African Health Products Regulatory Authority (SAHPRA), Medsafe (New Zealand), the Ministry of Food and Drug Safety (MFDS, South Korea), the Pharmaceuticals and Medical Devices Agency (PMDA, Japan), Swissmedic (Switzerland), the Taiwan Food and Drug Administration (TFDA), Therapeutic Goods Administration (TGA, Australia), the United States Food and Drug Administration (USFDA), as well as an observer from the World Health Organization (WHO). As part of their ongoing work, this group has previously published the results of a survey of the BCS-based biowaiver requirements of participating members(1).

The acceptance of foreign comparator or reference products is one of the topics addressed in the BEWGG since it could be considered the most limiting factor for the development and regulatory assessment of generic medicines marketed globally. Generic companies commonly have to repeat bioequivalence studies with the respective local comparator products of each country or jurisdiction because regulatory agencies are either unaware if the comparator product from other countries is the same product as their own or, if this is known, are unable to use that information for reasons of confidentiality and/or legal restrictions. This results in the duplication of efforts by regulators and industry alike, as well as unnecessary risks to study subjects.

The objective of this paper is to describe the current regulatory requirements with respect to the acceptability of foreign comparator products of oral dosage forms among the regulators/agencies that participate actively in the BEWGG and to identify those participants that may accept a foreign comparator product under certain conditions. The sharing of this information is a first step towards regulatory convergence in this area.

\section{MATERIALS AND METHODS}

The BEWGG conducted a survey of the acceptability and conditions related to the use of foreign comparator products in bioequivalence studies of oral dosage forms. This paper does not cover situations where the local comparator product is not available and an alternative comparator product has to be chosen. This information was obtained from the participating regulatory authorities and organizations in the BEWGG and is based on their respective regulatory guidance documents and policies (221).

Table 1. Comparison of General Aspects of Foreign Comparator Product Acceptance (Y: Yes; N: No)

\begin{tabular}{|c|c|c|c|c|c|c|c|c|c|c|c|c|c|c|c|}
\hline General aspects & 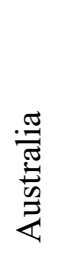 & 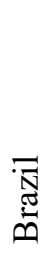 & 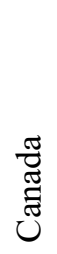 & $\frac{. \frac{\pi}{0}}{\frac{0}{0}}$ & 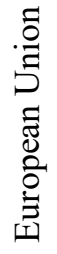 & 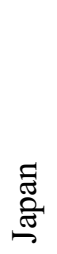 & 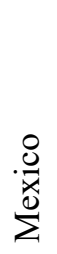 & 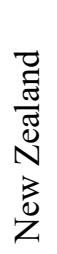 & 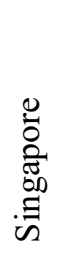 & 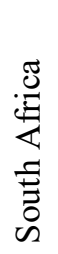 & 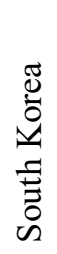 & 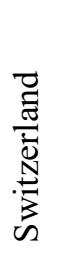 & . & $\mathscr{D}$ & $\stackrel{0}{\stackrel{0}{3}}$ \\
\hline $\begin{array}{l}\text { Accept BE studies using } \\
\text { foreign comparator } \\
\text { products (under certain } \\
\text { conditions) }\end{array}$ & $\mathrm{Y}$ & $\mathrm{N}$ & $\mathrm{Y}$ & $\mathrm{N}$ & $\mathrm{N}$ & $\mathrm{N}$ & $\mathrm{N}$ & $\mathrm{Y}$ & $\mathrm{Y}$ & $\mathrm{Y}$ & $\mathrm{N}$ & $\mathrm{Y}$ & $\mathrm{Y}$ & $\mathrm{N}$ & $\mathrm{Y}$ \\
\hline $\begin{array}{l}\text { Has a positive list of } \\
\text { acceptable foreign } \\
\text { comparators }\end{array}$ & $\mathrm{N}$ & - & $\mathrm{N}$ & - & - & - & - & $\mathrm{N}$ & $\mathrm{N}$ & $\mathrm{N}$ & - & $\mathrm{N}$ & $\mathrm{N}$ & - & $\mathrm{Y}$ \\
\hline
\end{tabular}




\section{RESULTS}

\section{General aspects}

Brazil, Colombia, the European Union member states, Japan, Mexico, South Korea and the United States do not accept foreign comparators and accept bioequivalence studies involving only their local comparator products, i.e. comparator products sourced from within their corresponding jurisdictions. In contrast, Australia, Canada, New Zealand, Singapore, South Africa, Switzerland and Taiwan accept studies with foreign comparator products under certain conditions, as discussed later in this article. Only the WHO lists specific comparators from different countries for the Prequalification of Medicines and for developing generics of essential medicines.

\section{Origin of the foreign comparator product}

Most participants limit the origin of the foreign comparator to countries with a comparable regulatory system. Australia, Canada and New Zealand have not defined the countries. WHO selects the products from those countries that are one of the founding members of International Council for Harmonisation of Technical Requirements for Pharmaceuticals for Human Use (ICH), if available. Switzerland accepts comparator products from the European Union, USA, Japan, Canada, Australia, Singapore and New Zealand. South Africa limits the foreign comparators to those procured in countries with which it aligns, based on ICH status (founding and standing regulatory members) or legally binding mutual contracts.

On the other hand, some participants do not impose any restrictions relating to the comparability of regulatory systems or agreements with the originating country or jurisdiction. Instead, emphasis is placed on comparing the manufacturing sites of the foreign and local comparator products. Taiwan requires the foreign comparator to be manufactured in the same manufacturing plant as the local comparator. If the manufacturing site information is not shown in the labelling of the foreign comparator, the dissolution profiles of the foreign and local comparators must be shown to be similar. Singapore highly recommends that the comparator used in the $\mathrm{BE}$ study be the same as the local comparator. However, if a foreign comparator is used and it is manufactured at a different manufacturing plant than the local comparator product or if it cannot be determined to be from the same manufacturing plant as the local comparator product, then the foreign comparator must exhibit similarity in comparative dissolution profiles with the local comparator.

In addition to country-level requirements, some jurisdictions also have requirements at the company level. Australia, Canada, Singapore, South Africa, Switzerland and Taiwan require that the foreign comparator and the local comparator have to be marketed by the same corporate entity. Australia, New Zealand, Singapore and South Africa also accept a different corporate entity if there is a licensing arrangement between the local and the foreign companies.

\section{Additional restrictions}

Some countries have specific restrictions specific to drug substance or drug product properties which additionally govern the situations in which foreign comparator products can or cannot be used.

In terms of drug substance properties, Australia does not accept foreign comparator products containing narrow therapeutic index drugs (NTIDs) or drugs with complicated pharmacokinetics, variable or incomplete absorption or absorption window or substantial first pass metabolism.

Table 2. Comparison of Requirements Regarding the Origin of Foreign Comparator Product (Y: Yes; N: No, N/A: Not Applicable) $^{\mathrm{a}}$

\begin{tabular}{|c|c|c|c|c|c|c|c|c|}
\hline $\begin{array}{l}\text { Origin of foreign } \\
\text { products }\end{array}$ & 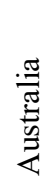 & Ũ & Z & 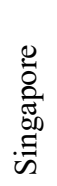 & 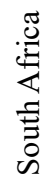 & 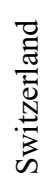 & 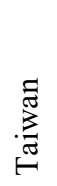 & $\stackrel{0}{\stackrel{0}{3}}$ \\
\hline $\begin{array}{l}\text { Restricted to countries/regions with a } \\
\text { comparable regulatory system }\end{array}$ & $\mathrm{Y}$ & $\mathrm{Y}$ & $\mathrm{Y}$ & $\mathrm{N}$ & $\mathrm{Y}$ & $\mathrm{Y}$ & $\mathrm{N}$ & (NA) \\
\hline Has a positive list of countries/regions & $\mathrm{N}$ & $\mathrm{N}$ & $\mathrm{N}$ & $\mathrm{N}$ & $\mathrm{Y}$ & $\mathrm{Y}$ & $\mathrm{N}$ & (NA) \\
\hline $\begin{array}{l}\text { From same corporate entity as local } \\
\text { comparator product }\end{array}$ & $\mathrm{Y}$ & $\mathrm{Y}$ & $\mathrm{Y}$ & $\mathrm{Y}$ & $\mathrm{Y}$ & $\mathrm{Y}$ & $\mathrm{Y}$ & (NA) \\
\hline
\end{tabular}


Canada does not accept foreign comparator products containing NTIDs or drugs that require patient monitoring in order to avoid the consequences of under- or over-treatment. Singapore does not accept foreign comparator products that are NTIDs for similar reasons. Canada also limits the acceptance of foreign comparator products to those that contain highly soluble drugs. In contrast, there are no exclusion criteria with respect to drug substance properties in New Zealand, South Africa, Switzerland and Taiwan.

New Zealand, Singapore, South Africa, Switzerland and Taiwan do not have restrictions based on the release profile of the drug product. Canada only accepts foreign comparator products for immediate release formulations. Australia accepts immediate and enteric/delayed release products and may accept a foreign comparator product for sustained release products on a caseby-case basis, but a higher level of evidence is required to show identicality with the local comparator product. To this end, Australia states "As the information relating to the manufacturing method of a reference product is usually not known to sponsors of generic medicines, the burden of proof to unequivocally demonstrate that the sustained release products are identical may be practically unfeasible".

In Australia, Canada, New Zealand, South Africa, Switzerland and Taiwan a foreign comparator of oral suspensions can be accepted, but the formulation and the physicochemical properties (including particle size distributions of the suspended drug substance) should be compared. In contrast, foreign comparator products are not necessary in Singapore for suspensions because they are regarded as oral solutions and qualify for a biowaiver.

\section{Supportive documentation}

Australia, Canada, New Zealand, South Africa, Switzerland and Taiwan require applicants to provide the name and address of the foreign innovator company, details regarding the source of supply (i.e., address of the wholesaler or pharmacy where the foreign product was obtained), authorisation number of the foreign comparator, batch number and expiry date. In South Africa, Switzerland and the WHO Prequalification Programme of Medicines, applicants must submit a copy of the purchase invoice, where the date and place of purchase or address of the distributor must be clearly visible, as well as documentation verifying the method of shipment (from the distributor to the sponsor and the CRO where the bioequivalence study was conducted) and storage conditions of the comparator product (from the time of purchase to the time of study initiation).

The labelling of the foreign comparator product (i.e., product information, consumer medicine information (often the package insert/leaflet) and container labels) is required by Australia, Canada, South Africa and Taiwan, but it is not required by New Zealand and Switzerland.

Table 3. Comparison of Additional Restrictions for Accepting Foreign Comparator Products (Y: Yes; N: No) ${ }^{\mathrm{a}}$

\begin{tabular}{|c|c|c|c|c|c|c|c|c|}
\hline Additional restrictions & 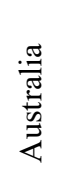 & 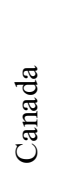 & 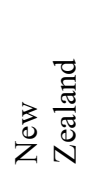 & 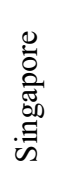 & 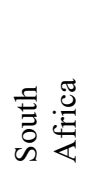 & 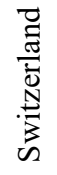 & 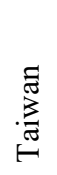 & $\stackrel{0}{3}$ \\
\hline \multicolumn{9}{|l|}{ Drug substance properties } \\
\hline NTID & $\mathrm{Y}$ & $Y^{c}$ & $\mathrm{~N}$ & $\mathrm{Y}$ & $\mathrm{N}$ & $\mathrm{N}$ & $\mathrm{N}$ & $\mathrm{N}$ \\
\hline $\begin{array}{l}\text { Complicated PK, variable/incomplete } \\
\text { absorption, substantial first pass } \\
\text { metabolism }\end{array}$ & Y & $\mathrm{Y}^{\mathrm{c}}$ & $\mathrm{N}$ & $\mathrm{N}$ & $\mathrm{N}$ & $\mathrm{N}$ & $\mathrm{N}$ & $\mathrm{N}$ \\
\hline \multicolumn{9}{|l|}{ Drug product properties } \\
\hline Immediate-release & $\mathrm{N}$ & $\mathrm{N}$ & $\mathrm{N}$ & $\mathrm{N}$ & $\mathrm{N}$ & $\mathrm{N}$ & $\mathrm{N}$ & $\mathrm{N}$ \\
\hline Delayed-release & $\mathrm{N}$ & $\mathrm{Y}$ & $\mathrm{N}$ & $\mathrm{N}$ & $\mathrm{N}$ & $\mathrm{N}$ & $\mathrm{N}$ & $\mathrm{N}$ \\
\hline Sustained-release & $\mathrm{N}^{\mathrm{b}}$ & $\mathrm{Y}$ & $\mathrm{N}$ & $\mathrm{N}$ & $\mathrm{N}$ & $\mathrm{N}$ & $\mathrm{N}$ & $\mathrm{N}$ \\
\hline \multicolumn{9}{|c|}{$\begin{array}{l}\text { a Brazil, Colombia, the EU, Japan, Mexico, South Korea and US are not mentioned in this table as they do not currently } \\
\text { accept foreign comparator products. } \\
\text { b Case-by-case basis } \\
\text { c Also limited to high solubility drugs }\end{array}$} \\
\hline
\end{tabular}


In Canada, Singapore and the WHO Prequalification Programme of Medicines, applicants must submit a copy of the comparator product's labelling, where the name of the product, name and address of the manufacturer, batch number, and expiry date should be clearly visible.

All these seven countries require the certificate of analysis (CoA) of the foreign comparator product batch employed in the bioequivalence study. Australia and South Africa also require the $\mathrm{CoA}$ of the local comparator product. Canada requires that product samples in their original container closure systems be made available upon request. None of the other participants require samples of the foreign comparator product in the original container.

In New Zealand, reduced data requirements are applied to foreign comparator products sourced from the Australian market, provided evidence of harmonisation of the comparator product between the two markets can be demonstrated. Acceptable evidence supporting harmonisation between the New Zealand and Australian innovator products includes copies of the labelling or package inserts that demonstrate co-marketing in both countries.

\section{Comparison of comparator product characteristics}

The formulations of the local and the foreign comparator product should be compared for all participants.
For Australia, Canada and New Zealand the local and the foreign comparator product have to have the same size, weight, shape, colour, scoring and type of coating. In contrast, Taiwan only requires them to have the same size, weight and type of coating, Switzerland requires them to have only the same size and weight, and Singapore and South Africa may accept differences as long as the release type is the same.

All of these participants except South Africa also require the foreign comparator employed in the bioequivalence study to have the same strength as the local one. South Africa allows the foreign comparator product used in the bioequivalence study to have a different strength from the local comparator product as long as the dose administered in the study is within the approved dosage regimen, because the full range of product strengths of the innovator products are not always marketed in South Africa.

Australia is the only jurisdiction that requires a quantitative analysis in sufficient batches to determine batch-to-batch variability (often 2-3 batches) using validated test methods, whereas all seven countries only require a qualitative comparison. As part of the validation of the test methods used, three batches of the proposed product should be tested with the test methods to demonstrate that the results obtained are both accurate and precise.

Table 4. Comparison of the Supportive Documentation for Foreign Comparator Products (Y: Yes; N: No) ${ }^{\mathrm{a}}$

\begin{tabular}{|c|c|c|c|c|c|c|c|c|}
\hline Batch-specific documentary requirements & 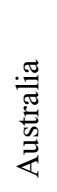 & 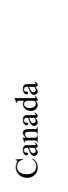 & 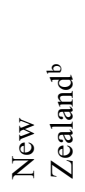 & 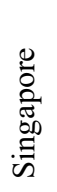 & 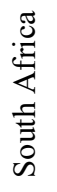 & 莺 & 离 & $\stackrel{0}{\stackrel{0}{3}}$ \\
\hline \multicolumn{9}{|l|}{ Details of foreign comparator } \\
\hline Name and address of MAH/manufacturer & $\mathrm{Y}$ & $\mathrm{Y}$ & $\mathrm{Y}$ & Y & $\mathrm{Y}$ & $\mathrm{Y}$ & $\mathrm{Y}$ & $\mathrm{Y}$ \\
\hline State source of supply & $\mathrm{Y}$ & $\mathrm{Y}$ & $\mathrm{Y}$ & $\mathrm{N}$ & Y & $\mathrm{Y}$ & $\mathrm{Y}$ & $\mathrm{Y}$ \\
\hline Purchase invoice & $\mathrm{N}$ & $\mathrm{N}$ & $\mathrm{N}$ & $\mathrm{N}$ & Y & Y & $\mathrm{N}$ & Y \\
\hline Authorisation number & Y & $\mathrm{Y}$ & $\mathrm{Y}$ & $\mathrm{N}$ & $\mathrm{Y}$ & $\mathrm{Y}$ & Y & $\mathrm{N}$ \\
\hline Batch number & Y & $\mathrm{Y}$ & $\mathrm{Y}$ & Y & $\mathrm{Y}$ & $\mathrm{Y}$ & $\mathrm{Y}$ & $\mathrm{Y}$ \\
\hline Expiry date & Y & $\mathrm{Y}$ & Y & Y & $\mathrm{Y}$ & $\mathrm{Y}$ & Y & $\mathrm{Y}$ \\
\hline Product labelling of foreign comparator & $\mathrm{Y}$ & Y & $\mathrm{N}$ & Y & Y & $\mathrm{N}$ & Y & $\mathrm{Y}$ \\
\hline Certificate of analysis (CoA) & $\mathrm{Y}$ & $\mathrm{Y}$ & Y & $\mathrm{Y}$ & $\mathrm{Y}$ & $\mathrm{Y}$ & Y & $\mathrm{Y}$ \\
\hline Physical samples in original container & $\mathrm{N}$ & $Y^{c}$ & $\mathrm{~N}$ & $\mathrm{~N}$ & $\mathrm{~N}$ & $\mathrm{~N}$ & $\mathrm{~N}$ & $\mathrm{~N}$ \\
\hline \multicolumn{9}{|c|}{ 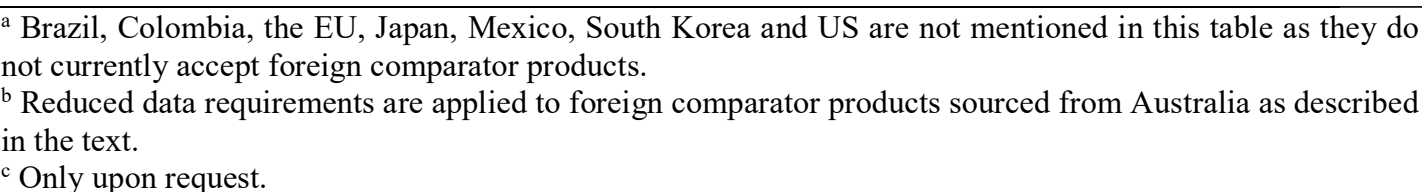 } \\
\hline
\end{tabular}


Australia, New Zealand, Switzerland and Taiwan also require some physicochemical testing such as Fourier transform infrared spectra, near infrared spectra and powder X-ray diffraction spectra.

In Australia, Canada, New Zealand, Singapore, South Africa, Switzerland and Taiwan, it is necessary to demonstrate that the local and the foreign comparator product have similar dissolution profiles across the physiological $\mathrm{pH}$ range with 12 individual units per product. However, if it can be shown that the manufacturing site of the foreign and local comparator products are the same, then comparative dissolution data are not required by Singapore and Taiwan. Similarly, in New Zealand, if the foreign comparator product is sourced from the Australian market and harmonisation between the comparator products from New Zealand and Australia has been established, then physicochemical testing (e.g., dissolution, FTIR and XRD) is not required.

\section{DISCUSSION}

These results demonstrate that the acceptability of foreign comparator products among BEWGG participants is not harmonised. While some countries do not accept this practice, other countries are open to the possibility of accepting foreign comparator products under certain conditions. However, the requirements to demonstrate that the foreign comparator and the local comparator are the same product in these countries differ widely. For instance, in Canada it is limited to highly soluble drugs with a wide therapeutic range in immediate release products. Also, Australia has the unique requirement for quantitative comparison of the composition. In contrast, the use of a foreign comparator has fewer requirements in New Zealand, Singapore, South Africa, Switzerland and Taiwan. In spite of these differences, similar dissolution profiles in the physiological $\mathrm{pH}$ range are essential for all countries.

In the WHO prequalification programme the comparator product must be procured from the market of a founding ICH member or observer, if available. However, in those cases where the innovator is an older product, a specific market and manufacturer is identified because there may be differences between products marketed in different markets (e.g., Novartis/Sandoz's rifampicin product in the US and the European Union are different formulations - while it is the accepted comparator for Europe, it is not for the United States, where the Sanofi-Aventis product is the reference standard). Importantly, for the WHO Prequalification Programme, both the European and the US comparator products are considered to be valid comparators because they ensure "prescribability", i.e., an adequate safety and efficacy profile, even if they might exhibit

Table 5. Comparison of the Requirements Related to Comparator Product Characteristics (Y: Yes; N: No, N/A: Not Applicable) ${ }^{\mathrm{a}}$

\begin{tabular}{|c|c|c|c|c|c|c|c|c|}
\hline $\begin{array}{l}\text { Comparing requirements for comparator product } \\
\text { characteristics }\end{array}$ & 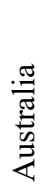 & 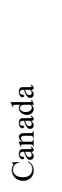 & 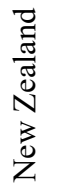 & 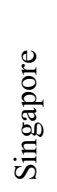 & 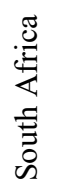 & 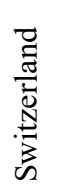 & 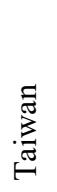 & 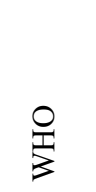 \\
\hline Qualitative comparison & & & & & & & & (NA) \\
\hline Size, weight & $\mathrm{Y}$ & $\mathrm{Y}$ & Y & $\mathrm{N}$ & $\mathrm{N}$ & $\mathrm{Y}$ & $\mathrm{Y}$ & \\
\hline Shape & $\mathrm{Y}$ & $\mathrm{Y}$ & $\mathrm{Y}$ & $\mathrm{N}$ & $\mathrm{N}$ & $\mathrm{N}$ & $\mathrm{N}$ & \\
\hline Colour & $\mathrm{Y}$ & $\mathrm{Y}$ & $\mathrm{Y}$ & $\mathrm{N}$ & $\mathrm{N}$ & $\mathrm{N}$ & $\mathrm{N}$ & \\
\hline Scoring & $\mathrm{Y}$ & $\mathrm{Y}$ & $\mathrm{Y}$ & $\mathrm{N}$ & $\mathrm{N}$ & $\mathrm{N}$ & $\mathrm{N}$ & \\
\hline Type of coating & Y & $\mathrm{Y}$ & $\mathrm{Y}$ & $\mathrm{N}$ & $\mathrm{N}$ & $\mathrm{N}$ & Y & \\
\hline Excipient composition & $\mathrm{Y}$ & $\mathrm{Y}$ & Y & Y & Y & Y & $\mathrm{Y}$ & \\
\hline Quantitative comparison & Y & $\mathrm{Y}^{\mathrm{c}}$ & $\mathrm{N}$ & $\mathrm{N}$ & $\mathrm{N}$ & $\mathrm{N}$ & $\mathrm{N}$ & (NA) \\
\hline Dissolution testing & $\mathrm{Y}$ & $\mathrm{Y}$ & $\mathrm{Y}^{\mathrm{b}}$ & $\mathrm{Y}$ & $\mathrm{Y}$ & Y & Y & (NA) \\
\hline Physicochemical testing other than dissolution & $\mathrm{Y}$ & $\mathrm{Y}$ & $\mathrm{Y}^{\mathrm{b}}$ & $\mathrm{N}$ & $\mathrm{N}$ & Y & $\mathrm{Y}$ & (NA) \\
\hline \multicolumn{9}{|c|}{$\begin{array}{l}\text { a Brazil, Colombia, the EU, Japan, Mexico, South Korea and US are not mentioned in this table as they do not } \\
\text { currently accept foreign comparator products. } \\
\text { b Reduced data requirements are applied to foreign comparator products sourced from Australia as described in the } \\
\text { text. } \\
\text { c Only for suspensions, or powders for inhalation. }\end{array}$} \\
\hline
\end{tabular}


different bioavailability and, consequently, the generics approved based on a comparison with the US comparator may not be "switchable" with the generics approved based on a comparison with the European comparator.

It is interesting to note that the criteria of the BEWGG members appear to correlate reasonably well with the market size of the jurisdiction. Those jurisdictions with a large population (more than a hundred million inhabitants, e.g., European Union: 512, United States: 309, Brazil: 204, Japan: 127 and Mexico: 113) require bioequivalence studies with their local comparator and generic companies are able to conduct the studies because they are profitable with those market sizes. In contrast, those countries with a smaller market size (New Zealand: 4.6 million inhabitants, Singapore: 5.6, Switzerland: 8, Taiwan: 23, Australia: 25, Canada: 36) are open to accept bioequivalence studies with foreign comparators if these appear to be the same as the local ones. In those countries with middle size, the purchasing power of the population and the availability of local manufacturers may also play a role - South Africa (53 million) may accept foreign comparators, whereas Colombia (49 million) and South Korea (51 million) do not. Similarly, Australia and Canada, with 25 and 36 million inhabitants, respectively, impose important limitations for the acceptability of the foreign comparator. In countries that are smaller and with lower purchasing power than those participating in the BEWGG, it can be expected that generic products would not be developed with the local comparator products because those markets are not considered profitable enough for generic companies (e.g. Zimbabwe) (22). These countries generally align with the WHO and accept studies conducted with comparators from founding ICH countries under the assumption that they will be the same in all ICH countries, without any additional requirements as long as this foreign comparator is marketed by the innovator company.

Accepting foreign comparator products may bring about public health benefits by increasing the availability of generic medicines and thereby reducing healthcare costs. By decreasing the number of bioequivalence studies that industry is required to perform, regulators are able to lower barriers to generic drug applications while still maintaining the integrity and standards of safe, effective and quality generic products available for the people within their jurisdiction. On the other hand, the acceptance of foreign comparators in BE studies does have some risk in that the product may not be the same as the local comparator and may thus bring about switchability issues. Where a jurisdiction accepts the use of a foreign comparator, they apply restrictions to control the risk associated with switchability issues. Since greater restrictions on the use of a foreign comparator may also increase barriers to market entry for generic drug products, each jurisdiction must determine the appropriate approach for their health care system.

Those countries that require the exclusive use of their local comparator do so to ensure "switchability" of all approved generics in their markets. Interestingly, while the European Union does not accept comparator products from outside Europe, this approach contrasts sharply with the approach taken within the European Union, where the legislation requires all member States to accept the comparator product from the market of any other member State. This acceptance is required without any demonstration that the comparators from all member States are the same or even when evidence is available confirming that they are not the same, since all the comparator products marketed in the European Union are considered safe and efficacious, i.e., "prescribable". The legislation of the European Union does not consider the "switchability" of the medicinal products, which is the responsibility of the individual member States and, therefore, the lack of "switchability" cannot be raised to preclude the approval of a generic product.

For countries whose regulatory systems allow them to accept foreign comparator products, the acceptability of foreign comparator products is complicated by the absence of data confirming that the foreign comparator is identical to the local one. The sharing of confidential business information such as the composition, manufacturing process and specifications of the comparator products between regulators is not allowed by the present legislation of most countries. It would thus be necessary to obtain permission from the owner of the comparator product in order to share this information. However, it can be expected that the comparator product owner will be reluctant to provide consent in order to avoid competition from generic companies. To overcome this obstacle, the legal systems would need to be modified to allow regulatory agencies to share needed confidential information about comparator products with other regulatory agencies.

Another potential approach to enhanced acceptance of foreign comparator products through sharing of information could involve the use of an independent third party (such as the WHO) who could determine the similarity of comparator products. If each jurisdiction shared the needed 
information concerning their local comparator product with the third party, it would then be possible to ask the third party if the products from two markets are similar or the same based on a predefined criterion without sharing the information with individual countries. This assessment could be based on the raw material specifications, qualitative and quantitative composition of the product, manufacturing process, manufacturing plant and finished product specifications. In this scenario, it would not be necessary to require the generic company to perform any comparability tests such as quantitative composition, dissolution profiles, Fourier-transform infrared spectroscopy (FTIR), near infrared spectroscopy (NIR) and powder Xray diffraction (XRD), and restrictions on the acceptance of a foreign comparator could likely be eliminated.

\section{CONCLUSION}

The criteria for the acceptance of foreign comparator products of BEWGG participants vary widely and consensus may be very complicated from a legal point of view. Without sharing information between countries it is difficult to guarantee that the comparator products from two different countries are identical. Some countries will accept foreign comparator products under certain conditions, but others do not accept foreign comparator products at all. Some regulators have chosen to accept foreign comparator products; this reduces the number of unnecessary studies while increasing the availability of generic medicines in their countries, which may contribute towards lowering healthcare costs. In the presence of barriers which inhibit the acceptance of foreign comparator products (such as the absence of agreements for sharing information about the composition and manufacturing of the comparator products among those regulators that accept foreign comparator products), it will continue to be necessary to perform bioequivalence studies using the local comparator, or in some cases, to conduct a battery of in vitro tests to demonstrate the similarity/identity of the local comparator product to the foreign comparator product used in a bioequivalence study.

\section{DISCLAIMER}

This manuscript represents the personal opinion of the authors and does not necessarily represent the views or policy of their corresponding regulatory agencies.

\section{REFERENCES}

1. Van Oudtshoorn et al. A Survey of the Regulatory Requirements for BCS-Based Biowaivers for Solid Oral Dosage Forms by Participating Regulators and Organisations of the International Generic Drug Regulators Programme. J Pharm Pharm Sci. 2018;21(1):27-37. doi: 10.18433/J3X93K. https://journals.library.ualberta.ca/jpps/index.php/J PPS/article/view/29579

2. Therapeutic Goods Administration (Australia). Part 6, Guidance 15 Biopharmaceutic Studies of the Australian Regulatory Guidelines for Prescription Medicines (April 2015). Available from: https://www.tga.gov.au/book/156-choicereference-product-bioequivalence-genericmedicines. Accessed on 8 November 2017.

3. Health Canada. Guidance Document: Use of a Foreign-sourced Reference Product as a Canadian Reference Product. Available from https://www.canada.ca/en/healthcanada/services/drugs-health-products/drugproducts/applications-submissions/guidancedocuments/canadian-reference-productguidance.html. Accessed on 31 January 2018.

4. Agência Nacional de Vigilância Sanitária (ANVISA) (Brazil). Law n. 9787, of 10th February 1999. Establishes the generic drugs in Brazil (1999). Available from: http://www2.camara.leg.br/legin/fed/lei/1999/lei9787-10-fevereiro-1999-351613-normaatualizadapl.pdf. Accessed on 14 November 2017.

5. Comisión Federal para la Protección contra Riesgos Sanitarios (COFEPRIS). Article 2, fraction XIV Bis, of the Reglamento de Insumos Para la Salud, (Health Products Regulation). Available from: http://www.diputados.gob.mx/LeyesBiblio/regley/ Reg_LGS_MIS.pdf.

http://www.cofepris.gob.mx/MJ/Documents/Regla mentos/rtoinsumos.pdf. Accessed on 29 November 2017.

6. Co-ordination Group for Mutual Recognition and Decentralised Procedures - Human. Question 8 of CMDh Questions and Answers. Generic Applications (CMDh/272/2012, Rev. 2) April 2017. Available from: http://www.hma.eu/fileadmin/dateien/Human_Me dicines/CMD_h_/Questions_Answers/CMDh_272 2012_clean.pdf. Accessed 29 November 2017.

7. Health Sciences Authority (Singapore). Appendix 10 Product Interchangeability and Biowaiver Request for Chemical Generic Applications, Guidance on Medicinal Product Registration in Singapore (November 2016). Available from: http://www.hsa.gov.sg/content/dam/HSA/HPRG/ Western_Medicine/Overview_Framework_Policie s/Guidelines_on_Drug_Registration/DR_Guide_2 016/DR\%20guide\%202016\%20final/Appendix $\% 2$ 010_Product\%20Interchangeability $\% 20$ and $\% 20 \mathrm{Bi}$ owaiver $\% 20$ Request $\% 20$ for $\% 20$ Chemical $\% 20 \mathrm{Ge}$ 
neric\%20Drug\%20Applications_30Nov16.pdf. Accessed on 8 November 2017.

8. Instituto Nacional de Vigilancia de Medicamentos y Alimentos (Colombia). Resolución 1124 de 2016. Por la cual se establece la Guía que contiene los criterios y requisitos para el estudio de Biodisponibilidad y Bioequivalencia de medicamentos, se define el listado de los que deben presentarlos y se establecen las condiciones de las Instituciones que los realicen (April 2016). Available from: https:/www.invima.gov.co/images/bioequivalenci a/Resolución\%201124\%20de\%202016.pdf.

Accessed on 8 November 2017.

9. South African Health Products Regulatory Authority (SAHPRA). General Information Registration of Medicines (August 2012). Available from: http://www.mccza.com/documents/1d9c57df2.01_ General_information_Jul12_v8_showing_changes. pdf. Accessed on 8 November 2017.

10. South African Health Products Regulatory Authority (SAHPRA). Pharmaceutical and Analytical CTD/eCTD (August 2014). Available from:

http://www.mccza.com/documents/751d10ba2.25

PA_CTD_Aug14_v4.pdf. Accessed on $2 \overline{9}$ November 2017.

11. South African Health Products Regulatory Authority (SAHPRA). Biostudies (June 2015). Available

from: http://www.mccza.com/documents/61de452d2.06 Biostudies_Jun15_v6.pdf. Accessed on $2 \overline{9}$ November 2017.

12. South African Health Products Regulatory Authority (SAHPRA). Dissolution (June 2015). Available from: http://www.mccza.com/documents/0ca3cfe72.07 Dissolution_Jun15_v5.pdf. Accessed on 29 November 2017.

13. Medsafe (New Zealand). Part 6: Bioequivalence of medicines, Guideline on the Regulation of Therapeutic Products in New Zealand (June 2015). Available from: http://www.medsafe.govt.nz/regulatory/Guideline/ GRTPNZ/bioequivalence-of-medicines.pdf. Accessed on 8 November 2017.

14. Ministry of Food and Drug Safety (South Korea). Standard on Pharmaceutical Equivalence Study; Notification No. 2017-28 (Apr. 19, 2017, Amended)].

15. Swissmedic (Switzerland) Instructions: Applications and authorisation for human medicines for known substances (May 2017). Available from: https://www.swissmedic.ch/ZL000_00_008e_VV. Accessed on 8 November 2017.

16. Taiwan Food and Drug Administration (Taiwan). Regulation of Bioavailability and Bioequivalence Studies, Ministry of Health and Welfare, Taiwan (March 2015). Available from:
http://law.moj.gov.tw/Eng//LawClass/LawContent .aspx?pcode $=$ L0030065. Accessed on 8 November 2017.

17. USFDA Draft Guidance for Industry: Referencing Approved Drug Products in ANDA submissions, January 2017. Available from: https://www.fda.gov/downloads/Drugs/GuidanceC omplianceRegulatoryInformation/Guidances/UC M536962.pdf.

18. The Drug Price Competition and Patent Term Restoration Act of 1984 (Pub. L. 98-417) (HatchWaxman Amendments) for generics

19. Title 21- Food and Drugs, 21 USC 355, (505(j), abbreviated new drug applications. Available from: http://uscode.house.gov/view.xhtml?req=\%28abbr eviated + new + drug + applications $\% 29 \& \mathrm{f}=$ treesort $\&$ $\mathrm{fq}=$ true $\&$ num $=2 \& \mathrm{hl}=$ true $\&$ edition $=$ prelim $\&$ granul eId=USC-prelim-title21-section355. Accessed on 14 November 2017.

20. WHO Essential Medicines and Health Products: Prequalification of Medicines. Bioequivalence: Guidance Documents, Application Forms \& Templates - Comparator products. Available from: https://extranet.who.int/prequal/content/whomedicines-prequalification-guidance. Accessed on 8 November 2017.

21. WHO Expert Committee on Specifications for Pharmaceutical Preparations. International Comparator Products List for equivalence assessment of interchangeable multisource (generic) products. In: Annex 11 Guidance on the selection of comparator pharmaceutical products for equivalence assessment of interchangeable multisource (generic) products. WHO Technical Report Series, No. 902, 2002. Available from: http://apps.who.int/medicinedocs/en/d/Jh3009e/9.5 .html. Accessed on 8 November 2017.

22. Gwaza L, Gordon J, Leufkens H, Stahl M, GarcíaArieta A. Global Harmonization of Comparator Products for Bioequivalence Studies. AAPS J. 2017; 19(3):603-606. doi: 10.1208/s12248-0170068-6. 